\title{
Bem-estar Psicológico e Inteligência Emocional entre Homens e Mulheres na Meia-idade e na Velhice
}

\author{
Nelma Caires Queroz. \\ Anita Liberalesso Neri ${ }^{12}$ \\ Universidade Estadual de Campinas
}

\begin{abstract}
Resumo
Investigamos relações entre bem-estar psicológico e inteligência emocional, em amostra de conveniência com 120 indivíduos, homens e mulheres, 60 de 45 a 55 e 60 de 60 a 69 anos. Instrumentos: duas escalas multidimensionais, Escala de Desenvolvimento Pessoal e Medida de Inteligência Emocional. Resultados: em automotivação e autoconsciência (MIE) os 2 grupos de idade masculinos pontuaram mais alto do que os femininos. Ocorreram correlações significantes entre automotivação (MIE) e auto-aceitação, propósito, crescimento pessoal, domínio e geratividade - manter e oferecer (EDEP). Análise fatorial da EDEP resultou em 5 fatores que separaram as competências relacionadas ao autodesenvolvimento e às relações interpessoais. Bem-estar psicológico e inteligência emocional não se comportaram como construtos independentes e nem foram consistentemente afetados por gênero e idade.

Palavras-chave: Bem-estar psicológico; inteligência emocional; meia-idade; velhice; gênero.
\end{abstract}

Emotional Intelligence and Psychological Well-being among Middle-aged and Old Men and Women

\begin{abstract}
There was carryed out a descriptive study aimed at investigate relations between psychological well-being and emotional intelligence. There was a convenience sample with 60 middle aged (45-55) and 60 old (60-69) males and females. Measures: Self-development Scale and Scale of Emotional Intelligence. Results: Male subjects scored higher than female on self motivation and self conscientiouness (MIE). There occurred significant relations between self motivation and self acceptation (MIE), and between self motivation and purpose, personal growing, mastery and generativity (maintenance and offering) (EDEP). Factorial analysis performed on EDEP resulted in five factors. Self development dimentions splited from others related to interpersonal relationships. Psychological well-being and emotional intelligence did not behave as independent constructs neither were consistently affected by gender and age.

Keywords: Psychological well-being; emotional intelligence; middle-age, old age, gender.
\end{abstract}

A tradição de estudar o ajustamento da personalidade do adulto em termos de auto-percepção de competência pessoal e de atendimento às normas sociais remonta a uma preocupação da comunidade científica (Allport, 1961; Bühler; 1935; Erikson, 1950; Jung,1933; Maslow; 1968; Rogers, 1961, citados em Ryff, 1989b), mas é recente o renascimento do interesse pelo assunto, dentro de uma perspectiva reconhecida como psicologia positiva (Neri, 2002; Seligman \& Csikzentmihalyi, 2000). Nesta perspectiva, a literatura especializada assume que o ajustamento pessoal tem como indicadores o bem-estar subjetivo e o bem-estar psicológico. Para Diener (1984), que usa indiscriminadamente os adjetivos subjetivo e psicológico, o bem-estar subjetivo é indicado por satisfação com a vida, por afetos positivos e negativos e por senso de felicidade.

Ryff (1989a, 1989b, 1995) discrimina entre bem-estar subjetivo e bem-estar psicológico, definindo este último em termos de competências do self, relacionadas porem diferentes de satisfação e afetos. A autora propôs um modelo teórico fundamentado no conceito aristotélico de eudaimonia, que significa busca de excelência pessoal, e não busca de prazer, como motivação central da existência. Com base nesse pressuposto e em estudos baseados em auto-relato e em análise fatorial, ela delineou um

\footnotetext{
${ }^{1}$ Pesquisa Financiada pela Fundação de Amparo a Pesquisa do Estado de São Paulo-FAPESP.

${ }^{2}$ Endereço para correspondência: Av. Bertrand Russell, 801, Cidade Universitária “Zeferino Vaz”; 13081 970, Campinas, SP. Fone: (19)37885585; Fax: (19)37885573.

E-mail:anitalbn@uol.com.br; nelcaires@yahoo.com.br
}

modelo composto por seis dimensões: autonomia (ter um self determinado e independente, capaz de realizar auto-avaliações com base em critérios pessoais e capaz de seguir as próprias opiniões); propósito de vida (ter objetivos na vida e senso de direção, administrando o passado e o presente, com metas significativas à vida); domínio do ambiente (ser capaz de administrar atividades complexas da vida, nos âmbitos profissional, familiar e pessoal); crescimento pessoal (ser capaz de manter continuamente o próprio processo de desenvolvimento, estar aberto às novas experiências, tendência à auto-realização, ao aperfeiçoamento e à realização das próprias potencialidades); autoaceitasão (ser capaz de aceitação de si e dos outros, com uma atitude positiva em relação a si mesmo e aos acontecimentos anteriores) e relações positivas com outros (manter relações de satisfação, de confiança e de afetividade com outras pessoas). O senso de bem-estar psicológico é determinado pela interação entre as oportunidades e as condições de vida, a maneira como as pessoas como organizam o conhecimento sobre si e sobre os outros e as formas como respondem às demandas pessoais e sociais. A consciência sobre a existência de um processo de constante deslocamento de metas em relação a objetivos mais elevados favorece o ajustamento e a maturidade individual (Keyes, Shmotkin \& Ryff, 2002). Keyes e colaboradores realizaram estudo investigando os construtos de bem-estar subjetivo e bem-estar psicológico. Os autores acreditavam que os construtos são conceitualmente relacionados, mas empiricamente separados e que as combinações desses relatos de bem-estar subjetivo e bem-estar psicológico diferem conforme aspectos sociodemográficos e de personalidade. A amostra foi composta por 3032 participantes 
americanos, sendo 48,5\% homens e 51,5\% mulheres. A mostra era composta por três grupos de idade: $33,2 \%$ adultos (25-39 anos), $46 \%$ de meia idade (40-59 anos) e 20,8\% idosos (60-74anos). No tratamento estatístico realizaram uma análise multivariada dos construtos bem-estar subjetivo e bem-estar psicológico por idade, nível de escolaridade, gênero, etnia e estado civil. Os resultados mostraram uma correlação estatisticamente significativa apenas para idade e nível de escolaridade. Adultos com baixo bem-estar subjetivo e elevado bem-estar psicológico tendem a ter maior grau de escolaridade do que adultos com a combinação de baixo bem-estar subjetivo e baixo bem-estar psicológico. Em contraste, adultos e idosos com elevado bem-estar subjetivo e baixo bem-estar psicológico tendem moderadamente a um menor grau de escolaridade do que adultos com a combinação de baixo bem-estar subjetivo e baixo bem-estar psicológico. Adultos e idosos com elevado bem-estar subjetivo e elevado bem-estar psicológico tendem a ter um nível mais alto de escolaridade do que adultos com a combinação de baixo bem-estar subjetivo e baixo bem estar psicológico. Os autores concluíram que as variáveis idade e nível de escolaridade exercem influência nas combinações de bem-estar, no qual se torna nítido que a idade que o indivíduo possui e o nível de escolaridade estão relacionados de acordo com valores de cada grupo social. Neste estudo, um elevado bem-estar é claramente vinculado à escolaridade e à idade: pessoas de meia idade e idosos que possuem alto nível de escolaridade são provavelmente mais prósperas na vida e têm melhor percepção da qualidade de sua vida.

Desde os seus primeiros escritos, nos anos 1950, Erikson demonstrou preocupação com o ajustamento psicossocial do indivíduo e os reflexos dessa condição sobre a sociedade. A introdução do conceito de geratividade em seu modelo de oito estágios do desenvolvimento foi uma contribuição precursora à compreensão do que hoje autores como Ryff (1989a, 1989b, 1995; Ryff \& Essex, 1991) designam como bem-estar psicológico. Para Erikson (1950, 1986, 1998), a geratividade manifesta-se de maneira mais intensa na meia-idade, como uma reação à estagnação no desenvolvimento da personalidade. O conceito inclui procriatividade, produtividade e criatividade, que se manifestam na geração de novos seres, de novos produtos e de novas idéias, e também num processo de autodesenvolvimento que se reflete na elaboração da identidade de adulto maduro. Para o autor, a geratividade é um indicador de ajustamento na meia-idade e na velhice e está relacionada ao cumprimento de tarefas evolutivas interna e culturalmente determinadas. McAdams e St. Aubin (1992) e McAdams, Hart e Maruna (1998) ampliaram o conceito de geratividade estabelecido por Erikson. Desenvolveram um modelo de geratividade que tem como base dois elementos: o primeiro é interno e corresponde à tendência ontogenética de garantir simbolicamente a própria imortalidade. O segundo é cultural e traduz as expectativas dos grupos humanos quanto à transmissão e à continuidade cultural. A partir desses dois elementos surgem sentimentos referenciados às preocupações pelo bem-estar atual e futuro da próxima geração, à crença no futuro da humanidade e ao compromisso com o bem-estar da humanidade. As ações gerativas são descritas pelos mesmos autores em termos de três dimensões conceituais: criação ou geração de indivíduos, coisas, ações e idéias que sirvam para perpetuar a espécie humana, no sentido biológico e sociocultural; manutenção, que se reflete em cuidar, amar, responsabilizar-se, cultivar, preservar, proteger, apoiar, ajudar, socorrer, promover e restaurar e se aplica a indivíduos, grupos, instituições, produtos culturais e à natureza e oferta, que se expressa na transmissão do que foi criado por meio do ensino, do aconselhamento, da orientação e da modelação e no deixar um legado pessoal, permitindo que os beneficiários dele desfrutem segundo seus próprios desígnios.

Ao longo dos últimos 100 anos, a comunidade científica vem construindo caminhos para melhor definir a inteligência e para estabelecer a natureza de suas interfaces com aspectos orgânicos, sociais, educacionais, psicológicos e culturais. Seus esforços refletemse em três grandes tendências, a psicométrica, a desenvolvimentalista e a cognitivista. A primeira prioriza as diferenças individuais quanto à capacidade de o indivíduo chegar a respostas precisas e corretas em situações de solução de problemas. A segunda enfatiza a maneira como os processos cognitivos se organizam, se estruturam ou mudam durante o desenvolvimento do ser humano. No enfoque do processamento da informação tenta-se compreender a inteligência humana em termos de processos mentais que colaboram para $\mathrm{O}$ desempenho de tarefas cognitivas, de modo especial a seleção, a codificação, o armazenamento e a evocação da informação (Almeida, Roazzi \& Spinillo, 1989).

Vários autores argumentam que esses modelos clássicos não dão conta da complexidade do funcionamento humano, que não se expressaria apenas na solução de problemas acadêmicos e do domínio do trabalho, mas também nos âmbitos social, emocional e do autoconhecimento. Entre eles citam-se Gardner (1994), Goleman (1995), Bar-On (1997, citado em Bar-on, 2002) e Salovey, Caruso e Mayer (2002). Gardner definiu competência intelectual como um conjunto de habilidades que capacitam o indivíduo a resolver problemas ou dificuldades, a criar produtos eficazes e a gerar novos problemas. Segundo o autor, a inteligência não é uma competência simples, mas complexa e multideterminada, que pode ser descrita em termos de pelo menos, sete dimensões, que ele denomina de inteligências múltiplas: lingüística, lógicomatemática, espacial, musical, corporal - cinestésica e pessoal. A inteligência pessoal divide-se em dois subtipos, a interpessoal e a intrapessoal. A primeira baseia-se na capacidade de perceber distinções nos outros, particularmente diferenças em estados de ânimo, motivações, intenções e temperamentos. Já a inteligência intrapessoal seria a capacidade de conhecimento de si mesmo, uma habilidade de discriminar emoções e sentimentos, utilizando esse conhecimento para orientar o próprio comportamento.

O conceito de inteligência emocional adquiriu popularidade com a publicação do livro de Goleman em 1995. Nesse campo, Hedlund e Sternberg (2002) afirmam que existem duas posições opostas. A primeira postula uma noção mais restrita, segundo a qual inteligência emocional é a capacidade de perceber e entender as informações emocionais. A inteligência emocional seria uma capacidade cognitiva ou aptidão (processamento adaptativo de informações emocionais) distinta de variáveis de personalidade. Aptidão é vista como a capacidade de reconhecer significados e 
de utilizar conhecimentos para raciocinar e resolver problemas (Mayer, Caruso \& Salovey 2002). Os adeptos da segunda posição assumem que a inteligência emocional inclui quase tudo que está associado com o êxito, em especial habilidades não cognitivas, tais como a assertividade e o controle de impulsos, que são em parte sobrepostas a traços de personalidade. A esse respeito, além do modelo de Goleman (1995), há o modelo misto de Bar-On (1997, citado em Hedlund \& Sternberg, 2002), que admite a existência de aptidões mentais, como por exemplo a solução de problemas, e de aptidões de personalidade, como por exemplo o otimismo. O próprio Goleman (1995) primeiro enfatizou na inteligência emocional as relações e as experiências cotidianas e a influência delas sobre o sucesso na solução dos problemas da vida diária. Depois, em 1999, definiu-a como capacidade de reconhecer os próprios sentimentos e os dos outros, de automotivar-se e de administrar as emoções nos âmbitos individual e interpessoal.

No Brasil, Siqueira, Barbosa e Alves (1999) construíram e validaram uma escala de inteligência emocional com 59 itens que avaliam cinco habilidades da inteligência emocional, conforme foram descritas nos modelos de Salovey e Mayer (1990) e de Goleman $(1995,1999)$. O conceito inclui um conjunto de cinco capacidades: autoconsciência, automotivação, autocontrole, empatia e sociabilidade. Empatia é definida pelos autores brasileiros como a facilidade em identificar os sentimentos, desejos, intenções, problemas, motivos e interesses dos outros, por intermédio da leitura e da compreensão de comportamentos não verbais de comunicação, tais como expressões faciais, tom de voz e postura corporal. Sociabilidade é a facilidade de iniciar e preservar as amizades, ser aceito pelas pessoas, valorizar as relações sociais, adaptar-se a situações novas, liderar, coordenar e orientar as ações das outras pessoas. Automotivasaão consiste na facilidade de elaborar planos para a própria vida, de modo a criar, acreditar, planejar, persistir e manter situações propícias para a concretização das metas futuras, com esperança e otimismo. Autocontrole é a facilidade de administrar os próprios sentimentos, impulsos, pensamentos e comportamentos e Autoconsciència relacionase à facilidade de lidar com os próprios sentimentos no que se refere à identificação, à nomeação, à avaliação, ao reconhecimento eà atenção a esses sentimentos. As três primeiras dizem respeito a reações do eu e a o que o indivíduo faz com seus sentimentos. São as bases psicológicas responsáveis pelo fortalecimento das estruturas internas do indivíduo. As duas últimas voltam-se para fora, em direção aos sentimentos dos outros e às interações sociais. Constituem os componentes psicossociais que asseguram a sua competência no mundo social.

O construto inteligência emocional tem merecido relativamente pouca atenção na literatura em parte porque não se originou na pesquisa básica, em parte porque aparentemente os seus termos se sobrepõem a outros correntes na pesquisa e na teorização sobre ajustamento e bem-estar psicológico. O presente estudo foi planejado com base no pressuposto de que há relações entre os dois conceitos e que investigá-las contribui para a teoria que embasará a formulação de estratégias de intervenção que favoreçam o desenvolvimento e o envelhecimento bem-sucedidos, tanto no âmbito individual, quanto no âmbito sociocultural.

\section{Objetivos}

Este estudo foi planejado para: a) identificar e descrever relações entre os construtos de inteligência emocional e de bem estar psicológico em pessoas que se encontram na meia idade e velhice; b) verificar as semelhanças e as diferenças entre os grupos etários e gênero quanto ao bem estar psicológico e inteligência emocional; e, c) descrever características e as relações psicométricas de dois instrumentos de avaliação psicológica frente à amostra estudada.

\section{Método}

\section{Participantes}

Amostra de conveniência composta por 120 participantes que apresentavam estilo de vida ativo e independente e que viviam na comunidade. Metade dos participantes tinha entre 45 e 55 anos (meia-idade) e a outra metade, de 60 a 69 anos (velhice). No grupo de idosos, a média de idade era de 64 anos e 2 meses ( $d p=3$ anos) e no grupo de meia-idade era de 49 anos e 9 meses ( $d p=2$ anos e 9 meses). Em cada grupo de idade, metade dos participantes era homem e metade era mulher. $\mathrm{Na}$ amostra, $46,6 \%$ do grupo de meia-idade e 51,6\% do grupo de idosos possuíam de 9 a 14 anos de escolaridade; eram casados $68 \%$ do sexo masculino e $41,5 \%$ do sexo feminino; dentre os solteiros, viúvos, separados e divorciados, $88 \%$ dos homens e $53 \%$ das mulheres viviam com um companheiro(a). Vinte e um por cento dos homens e igual porcentagem de mulheres eram aposentados, mas trabalhavam (dentre esses, $58 \%$ são do sexo masculino e $48 \%$ do sexo feminino; $10 \%$ estão na meia-idade e 33\% são idosos). Entre os trabalhadores ainda não aposentados, $83 \%$ pertenciam ao grupo de meia-idade e $23 \%$ ao de idosos. Os participantes foram convidados e indicados por outros, em seus locais de trabalho, em centros de convivência e em residências. Foram informados sobre a confidencialidade dos dados individuais e assinaram um termo de consentimento informado. Parte dos participantes responderam coletivamente e outros responderam individualmente.

\section{Instrumentos}

Ficha sóciodemográfica para coletar dados sobre gênero, idade, escolaridade, trabalho e aposentadoria.

Escala de Desenvolvimento Pessoal (EDEP), construída por Neri (1999), a partir das seis subescalas de bem-estar psicológico construídas por Ryff e colaboradores (1989a, 1989b, 1991, 1995), às quais foram acrescentados 12 itens avaliando geratividade (Erikson, 1950; McAdams \& St.Aubin, 1992), totalizando 30 itens de 5 pontos (de pouquíssimo a muitússimo). Destes, 18 referem-se às dimensões relações positiva com outros, autonomia, propósito de vida, crescimento pessoal, auto-aceitação, domínio do ambiente e 12 o conceito de geratividade e suas dimensões criar, manter e oferecer. Cada item é avaliado por uma escala de cinco pontos. 
Medida de Inteligencia Emocional - MIE, de Siqueira e colaboradores (1999) consiste em 59 itens escalares com quatro pontos cada um (1nunca; 2 - poucas vezes; 3 - muitas vezes; 4 - sempre), avaliando cinco dimensões fatoriais (empatia, sociabilidade, automotivação. Autocontrole e autoconsciência).

\section{Resultados}

A consistência interna dos instrumentos resultou num coeficiente $\alpha=0,90$ para a MIE, e, na EDEP, da ordem de 0,89 para os 18 itens de bem-estar psicológico e de 0,77 para os de geratividade. Esses índices indicam que os instrumentos possuem consistência interna. Segue-se a descrição dos resultados das análises univariadas e bivariadas. Por último, serão apresentados os dados da análise multivariada (fatorial).

$\mathrm{Na}$ comparação do desempenho dos grupos de idade e gênero na Medida de Inteligência Emocional (MIE), os grupos tiveram um desempenho parecido, isto é, não se observaram diferenças estatisticamente significantes quanto ao escore total na MIE. Quando foram considerados os escores das dimensões em separado, em automotivação ocorreu pontuação significativamente maior para os participantes do sexo masculino, independentemente da idade. Considerando-se o escore total e os escores nos domínios da EDEP, não ocorreram diferenças estatisticamente significantes entre os grupos de gênero e idade. Porém, quanto à dimensão manter, os homens e as mulheres de meia-idade pontuaram mais alto do que as mulheres e os homens idosos, embora a diferença não tenha sido estatisticamente significante $(p=0,06)$.

Tampouco foram encontradas correlações estatisticamente significantes entre os escores totais da amostra na EDEP e na MIE, o que sugere independência entre eles. Entretanto, esse resultado foi diferente quando foram calculadas as correlações entre o escore total de cada escala e os escores das dimensões de cada uma delas. Resultaram correlações estatisticamente significantes $(r=0,0001)$ entre o escore total na MIE e os escores nas seguintes dimensões da EDEP: propósito na vida, crescimento pessoal e auto-aceitação, dimensões essas que representam o bem-estar psicológico. Ocorreram correlações significantes entre o escore total na MIE e as dimensões criar e oferecer da subescala de geratividade da EDEP. Ocorreram relações estatisticamente significantes entre automotivação (MIE) e propósito na vida, crescimento pessoal, auto-aceitação e domínio sobre o ambiente, que pertencem à subescala de bem-estar psicológico, e entre automotivação e as dimensões criar e oferecer do construto geratividade (EDEP). A Tabela 1 detalha esses resultados.

Com o objetivo de estudar os padrões de inter-relação característicos dos desempenhos da amostra na EDEP, foi feita uma análise fatorial, com rotação ortogonal pelo método Varimax. O Coeficiente KMO foi 0,87, indicando que os dados têm consistência suficiente para submissão à análise fatorial. Pelo critério de seleção de fatores com valor próprio maior que 1 foram obtidos sete fatores que explicaram $61,7 \%$ da variabilidade total dos dados. Interpretamos os cinco primeiros, porque detinham as cargas mais altas e um maior número de itens, e porque melhor representavam os conceitos que presidiram a criação da EDEP. A seguir os fatores derivados da análise fatorial serão definidos (ver Tabela 2):

Fator 1 - Auto-realização, crescimento pessoal e ajustamento psicológico. O indivíduo tende a descrever a própria personalidade em termos de continuidade, integração e crescimento pessoal; abertura a novas experiências, realização das próprias potencialidades e perseguição de meta de excelência pessoal; Fator 2 - Produtividade. O centro de sentido desse fator é a contribuição singular que cada adulto maduro oferece ao seu grupo mais próximo e à sociedade de modo geral, contribuição essa que ocorre por meio de ação educativa (orientar). Não é apenas e simplesmente a produção de bens materiais, mas também a produção de bens espirituais, mediante os quais a continuidade e o progresso culturais ficam garantidos, ao mesmo tempo em que o indivíduo sobrevive na memória do grupo; Fator 3 - Cuidado. O prestar cuidados a indivíduos dependentes e a manutenção de relações de interdependência são ações e preocupações gerativas que fazem parte da agenda evolutiva dos adultos e dos idosos. As sociedades esperam que se manifestem no plano físico e no plano simbólico. $\mathrm{O}$ adulto cuja personalidade é congruente, tende a ver-se como necessário na vida de outrem e tende a comprometer-se com a educação em seu sentido mais lato de conduzir e orientar quanto a

Tabela 1

Distribuição das Correlações entre as Dimensões das duas Escalas (EDEP e MIE)

\begin{tabular}{lc}
\hline Variáveis & Correlação (Valores de R)* \\
\hline Domínio sobre o ambiente x automotivação & 0,61 \\
Propósito de vida x escore total na MIE & 0,52 \\
Propósito de vida x automotivação & 0,63 \\
Crescimento pessoal x escore total na MIE & 0,67 \\
Crescimento pessoal x automotivação & 0,65 \\
Auto-aceitação x escore total na MIE & 0,56 \\
Auto-aceitação x automotivação & 0,63 \\
Criar x escore total na MIE & 0,50 \\
Criar x automotivação & 0,50 \\
Oferecer x escore total na MIE & 0,56 \\
Oferecer x automotivação & 0,51 \\
\hline
\end{tabular}

Nota. *significativos a 0,0001 
Tabela 2

Estrutura Fatorial da Escala de Desenvolvimento Pessoal nos Grupos de Meia-idade e de Idosos

\begin{tabular}{lll}
\hline Fatores & $\begin{array}{c}\text { Cargas dos itens } \\
\text { no fator }\end{array}$ & Itens \\
Fator 1 & & \\
Auto -Realização & & \\
Crescimento Pessoal & & \\
Ajustamento Psicológico & 0,75 & 17 - Sou pessoa que caminha com confiança pela vida (Domínio) \\
& 0,73 & 05 - Conforme tempo passa estou cada vez melhor como pessoa (Cresc. Pessoal) \\
& 0,71 & 03 - Consigo enfrentar com vigor problemas do dia-a-dia (Propósito de vida) \\
& 0,70 & 12 - Tenho vários motivos para me sentir satisfeito com realizações (Auto-aceitação) \\
& 0,63 & 07 - Qdo. olho para trás e avalio vida, fico feliz que tudo deu certo (Auto-aceitação) \\
& 0,58 & 18 - Acho que ainda tenho muitas coisas para fazer (Sentido de vida) \\
& 0,56 & $04-$ Acho importantes ter novas experiências, ajudam compreender... (Cresc. Pessoal) \\
0,53 & 09 - Decido por mim mesmo (Autonomia) \\
& 0,50 & 02 - Sinto-me dono da minha vida (Domínio) \\
& 0,44 & 06 - Outros me descrevem como pessoa generosa, compartilhar... (Relaç. Posit. Outros) \\
& 0,43 & 11 - Sinto minha vida contínuo processo mudança, ... (Cresc. Pessoal) \\
\end{tabular}

Fator 2

Produtividade

$\begin{array}{ll}0,76 & 27-\text { Outros dizem que tenho contribuições criativas (Criar) } \\ 0,73 & 26-\text { Muitos me procuram para orientação (Oferecer) } \\ 0,62 & 29-\text { Após morrer gostaria ser lembrado ações/contribuições (Oferecer) } \\ 0,61 & 19-\text { Outros dizem que sou pessoa produtiva (Criar) }\end{array}$

Fator 3

Cuidado
0,66
24 - Sou necessário na vida de vários (Manter)
0,66 21 - Sinto tenho deixado minha marca nos outros (Oferecer)
0,50
08 - Gosto de vários aspectos minha personalidade (Auto-Aceitação)

Fator 4

Preocupação com as

próximas gerações.

\begin{tabular}{ll}
\hline 0,80 & $23-$ Penso pessoas se preocupam espécies,... não têm nada mais importante (Manter) \\
0,75 & $25-$ Qdo for velho, vou me recolher vida privada... (Oferecer) \\
0,68 & 28 - Prefiro não me envolver novos projetos (Criar) \\
\hline
\end{tabular}

Fator 5

Compromisso com o outro
0,77
22 - Sociedade é responsável destino pessoas carentes (Manter)
0,47
20 - Sinto tenho obrigação passar adiante experiência (Oferecer)
0,45
30 - Ensinar é uma das coisas mais lindas que existem (Oferecer)

Tabela 3

Estrutura Fatorial Resultante da Análise Conjunta dos Itens dos Fatores da Medida de Inteligência Emocional e da Escala de Desenvolvimento Pessoal

Novos fatores Composição dos novos fatores que representam relações entre a EDEP e a MIE

Fator 1 Altos valores em Auto-realização, crescimento pessoal e ajustamento psicológico (EDEP) da EDEP e na dimensão Automotivação da MIE

Fator 2 Altos valores em Compromisso com o Outro (EDEP) e na dimensão Empatia da MIE

Fator 3 Altos valores no Cuidado (EDEP) e na dimensão Autoconsciência da MIE, mas valores baixos no Autocontrole da MIE

Fator 4 Altos valores em Produtividade (EDEP) e na dimensão Sociabilidade da (MIE)

Fator 5 Altos valores em Preocupação com as próximas gerações (EDEP) e na dimensão Autoconsciência da (MIE) 
questões existenciais; Fator 4 - Preocupação com as próximas gerações. Manifesta-se pelo desejo de legar algo de si para os contemporâneos e para as gerações vindouras, sendo-se produtivo e cuidadoso em relação a eles; Fator 5 - Compromisso com o Outro. Reflete-se em preocupações com a continuidade biológica e cultural de indivíduos particulares e da sociedade de um modo geral.

$\mathrm{Na}$ análise de variância comparando os grupos de idade e gênero quanto ao seu comportamento nesses fatores, o único que se diferenciou foi o Fator 5, em que o grupo de meia-idade apresentou pontuação mais alta, independentemente de gênero. Ou seja, o grupo de meia-idade relatou ter maior compromisso com o outro do que o grupo de idosos.

Obteve-se correlação significante entre o Fator 1 da EDEP e o escore total da MIE e também entre esse Fator 1 e o escore em automotivação da MIE. Portanto, ajustamento psicológico, indicado por crescimento pessoal e auto-realização estão relacionados com a inteligência emocional, principalmente com a dimensão automotivação. Estas correlações foram corroboradas pela análise fatorial em que foram tratadas ao mesmo tempo as duas escalas. Os fatores que emergiram dessa análise sugerem que elas não são independentes, como se pode observar na Tabela 3.

\section{Discussão}

A literatura psicológica sempre discriminou entre as capacidades intelectuais que têm base orgânica, tais como processamento básico da informação, memória, atenção, e as competências sociais e emocionais relacionadas ao manejo de experiências práticas e relacionais, derivadas do acúmulo de vivências cotidianas. Mais recentemente, desenvolveu-se uma nova perspectiva que tenta juntar as duas tradições. Segundo a nova tradição, a inteligência prática, social e emocional, e que deriva das vivências das pessoas, tem como base as capacidades mentais básicas, embora seja relativamente independente delas. Como elas, também permite a adaptação do indivíduo, mediante a seleção e a transformação de aspectos do ambiente. Entre as capacidades intelectuais práticas, sociais e emocionais podem ser citadas, por exemplo, a definição e a transferência para a formulação de estratégias, a monitoração da ação e da solução de problemas e a avaliação (Sternberg \& Grigorenko, 2002). Incluem também as inteligências múltiplas de Gardner (1994) e a inteligência emocional de Goleman (1995).

O modelo de Ryff (1989b, 1995) é baseado numa concepção de maturidade como virtude ou qualidade de procurar realizar o próprio potencial para a excelência pessoal. Essa qualidade é apontada como maturidade, que assim se relaciona com os padrões sociais de adequação social e de excelência esperados para indivíduos adultos e idosos. No campo do desenvolvimento do adulto e do idoso, o termo maturidade é usado principalmente com três sentidos: cumprimento de normas etárias que o grupo dispõe para essas idades; alcance de uma qualidade ou virtude do ego e indicador de saúde mental na meia-idade e na velhice (Neri, 2002).

Nesta pesquisa, os escores relativos aos desempenhos da amostra na Escala de Desenvolvimento Pessoal (EDEP) e na Medida de
Inteligência Emocional (MIE) foram elevados, sugerindo que os participantes se vêem como ajustados ou como pessoas com um desenvolvimento positivo, ou como portadoras de alto grau de competência socio-emocional. Freire (2000) e Neri (2000) afirmam, com base na literatura, que pessoas de meia-idade e idosas são capazes de manter visões positivas de si mesmas, administrando suas vidas de forma eficaz, apesar das adversidades que fazem parte do processo de envelhecimento. São capazes de fazer ajustes de seus objetivos e metas para se adequarem à realidade social em que estão inseridas e á sua realidade interna. Tais ajustes são realizados com base nas experiências anteriores de sucesso e fracasso ao longo do curso de vida. A utilização de recursos internos e de estratégias de enfrentamento diante das dificuldades impulsiona a manutenção e a reestruturação do bem-estar psicológico. A inteligência emocional tem a sua importância porque está relacionada com a competência para reconhecer os próprios sentimentos e os dos outros, para administrar as próprias emoções e os relacionamentos e também se relaciona com a automotivação para lidar com as dificuldades encontradas no curso de vida.

Neste estudo não ocorreu correlação significativa entre os construtos globais bem-estar psicológico e inteligência emocional, mas sim entre algumas de suas dimensões. Entre as correlações encontradas destacam-se as relativas à automotivação e ao escore total de inteligência emocional e entre automotivação e as dimensões auto-aceitação, propósito na vida, crescimento pessoal, domínio sobre o ambiente, criar e oferecer, pertencentes à Escala de Desenvolvimento Pessoal. Ou seja, indivíduos automotivados para lidar com as dificuldades da vida relatam ter elevada auto-aceitação, elevados senso de crescimento pessoal, de propósito de vida e de controle sobre o ambiente, além de inclinação para ações gerativas. Isto indica que há sobreposição dessas dimensões pertencentes aos dois diferentes construtos e, se assim é, a automotivação atua tanto na estruturação interna do indivíduo como na externa. De fato, Gardner (1994) definiu inteligência interpessoal como a capacidade de perceber distinções em estados emocionais de outras pessoas, especialmente as que concernem a estados de ânimo, motivações, intenções e temperamento. Essa formulação é compatível com a proposição de Goleman (1995) e a de Siqueira, Barbosa e Alves (1999), que acreditam que as dimensões empatia e sociabilidade conectam o indivíduo com as relações externas. Acredita-se que a automotivação está na base da elaboração e da construção das interações sociais, bem como da manutenção das competências psicossociais, motivo pelo qual guarda correlações com as dimensões criar, oferecer e controle sobre o ambiente, do construto bem-estar psicológico. Para Gardner (1994), inteligência intrapessoal é um profundo conhecimento de si mesmo, uma habilidade de discriminar emoções e sentimentos, utilizando esse conhecimento para orientar o próprio comportamento. Fazendo relação com a teoria de Goleman (1995) e de Siqueira e colaboradores (1999), as dimensões autocontrole, autoconsciência e automotivação da inteligência emocional formam um conjunto de competências, direcionado às relações internas, à discriminação dos próprios sentimentos e à 
utilização desse conhecimento sobre si mesmo para o fortalecimento das estruturas internas do indivíduo.

Este estudo evidenciou que a automotivação é imprescindível ao equilibbrio das relações interpessoais e intrapessoais; ela é uma alavanca que impulsiona o indivíduo a elaborar planos para a própria vida, a buscar adaptações e recursos internos para lidar com as adversidades e a manter condições adequadas para a manutenção do bem-estar psicológico. Tais relações explicariam as correlações encontradas entre automotivação e crescimento pessoal, autoaceitação e propósito na vida. Ou seja, a automotivação é um importante preditor do bem-estar psicológico, é agente facilitador da elaboração e da concretização das metas futuras e é mantenedor do otimismo nas diversas fases da vida. Essas relações ficam ainda mais em evidência com a análise fatorial conjunta da Escala de Desenvolvimento Pessoal (EDEP) e a Medida de Inteligência Emocional (MIE), da qual derivaram cinco fatores. O Fator 1 (autorealização, crescimento pessoal, ajustamento psicológico) confirma a análise bivariada precedente, assim como o Fator 2 (compromisso com o outro e empatia), o Fator 5 (preocupação com as próximas gerações e autoconsciência) e o Fator 4 (produtividade e sociabilidade).

Comparando-se os grupos etários e de gênero quanto ao bemestar psicológico e à inteligência emocional, foram encontradas algumas diferenças significativas. Em inteligência emocional, os homens são mais automotivados do que as mulheres e há uma leve tendência dos homens também serem mais autoconscientes, independentemente da idade. $\mathrm{Na}$ Escala de Desenvolvimento Pessoal (EDEP), os homens do grupo de meia-idade apresentaram uma tendência de serem mais cuidadosos do que as mulheres de meiaidade. Pouco se conhece sobre os efeitos do envelhecimento sobre a inteligência emocional (Phillips, Maclean \& Allen, 2002). Em Bar-On (2002) é citado estudo de 1997 em que foi utilizado o Emotional Quotient Inventory (EQ-i), abrangendo as dimensões: aptidões intrapessoais (autoconsciência emocional, assertividade, auto-respeito, autorealização e independência); aptidões interpessoais (relacionamentos interpessoais, responsabilidade social, empatia); adaptabilidade (resolução de problemas, teste de realidade, flexibilidade); administração do estresse (tolerância ao estresse, controle de impulsos) e, por último, humor geral (felicidade e otimismo). A amostra focalizada tinha 4000 participantes com 17 anos e mais, residentes nos EUA e Canadá, sendo 49\% do sexo masculino e 51\% do feminino. Os grupos mais velhos apresentaram resultados significativamente mais altos do que os grupos mais jovens na maioria das dimensões da escala. Não apareceram diferenças entre homens e mulheres no que diz respeito à competência social e a competência emocional total. As mulheres apresentaram aptidões interpessoais mais fortes do que os homens, mas estes apresentaram mais alta capacidade intrapessoal e maior capacidade para administrar o estresse, além de serem mais adaptáveis.

No presente estudo não foram encontradas diferenças significativas entre os escores totais dos construtos bem-estar psicológico e inteligência emocional nos diferentes grupos de idade. Ambos os grupos pontuaram alto, o que é congruente com os dados na literatura que apontam que as pessoas que envelhecem atingem pontuações elevadas em escalas de auto-relato que avaliam bem-estar psicológico. Outro elemento que pode explicar as altas pontuações na amostra é a sua escolaridade, de 11 anos, em média. Segundo a literatura, quanto mais elevado o nível de escolaridade do indivíduo, maior o senso de bem-estar psicológico. Cachioni (2003) realizou um estudo com 102 professores de sete Universidades da Terceira Idade. Um de seus objetivos foi levantar auto-relatos sobre o desenvolvimento pessoal dos participantes. A autora utilizou a Escala de Desenvolvimento Pessoal (EDEP) e verificou que na amostra predominaram auto-relatos positivos sobre o desenvolvimento pessoal, principalmente entre os professores mais velhos e os da área social. A autora concluiu que a prática da docência a idosos proporcionava aos sujeitos trocas pessoais e culturais significativas, senso de integridade e de geratividade, e isso favoreceria o seu senso de bem-estar psicológico.

As médias elevadas dos dois grupos de idade na EDEP podem ter relação com a experiência de vida acumulada pelos sujeitos, experiência essa que pode estar contribuindo para a construção de estratégias de enfrentamento das condições de vida, parte das quais pode ser adversa. $\mathrm{O}$ conhecimento de si mesmo pode contribuir para o fortalecimento na construção de recursos internos e estes poderão promover o bem-estar na medida que o indivíduo tem condições de administrar os próprios sentimentos e comportamentos. Baltes e Mayer (1999) afirmam que o self é um sistema composto por estruturas de conhecimento de si mesmo, é um conjunto de funções cognitivas que integram ativamente essas estruturas ao longo do tempo. O self permite interpretar experiências e comportamentos e manejar e regular emoções. Tem estreita relação com o bem-estar psicológico e a qualidade de vida percebida que, em conjunto, favorecem o senso de continuidade. A avaliação do bem-estar psicológico na meia-idade e na velhice (assim como nas outras idades) depende do self, que é mantido ao longo de toda a vida, mesmo na presença de condições adversas.

Este foi um estudo preliminar, a despeito da relativa complexidade dos seus objetivos e de suas análises. Novos estudos deverão suprir suas lacunas, por exemplo, investindo na validação interna e externa da EDEP e, depois realizando pesquisas comparativas com amostras maiores e casualizadas, envolvendo várias faixas de idade e estilos de vida. Também será interessante realizar medidas comportamentais de desempenho na vida prática para ambas as medidas e buscar relações entre elas. Finalmente, parece relevante investir na avaliação do grau de validade preditiva dos mesmos instrumentos. Afora os aspectos psicométricos, o conhecimento em psicologia do desenvolvimento poderá beneficiar-se de estudos longitudinais ou de estudos com sequiências de coortes, que permitem controlar efeitos de variáveis educacionais e sócio-históricas. Os esforços deste trabalho e as conclusões que permitiu exemplificam o caráter acumulativo da pesquisa. Notar seus limites demonstra preocupação com a parcimônia, que deve nortear todo trabalho científico. Dar a ele publicidade significa permitir a crítica pelos iguais e a realização de novas investigações que irão refiná-lo ou contestá-lo. 


\section{Referências}

Almeida, L., Roazzi, A. \& Spinillo, A. (1989). O estudo da inteligência humana: Divergências, convergências e limitações dos modelos. Psicologia: Teoria e Pesquisa, $5,217-230$

Baltes, P. B. \& Mayer, K. U. (1999). The berlin aging study. Aging from 70 to 100. New York, NY: Cambridge University Press.

Bar-On, R. (2002). Inteligência social e emocional: Visões do emotional quotient inventory (R. C. Costa, Trad.). Em R. Bar-On \& J. D. A. Parker (Orgs.), Manual de inteligência emocional: Teoria, desenvolvimento, avaliação e aplicação em casa, na escola e no local de trabalho (pp. 266-283). Porto Alegre: Artmed. (Original publicado em 2000)

Cachioni, M. (2003). Crenças sobre desenvolvimento pessoal. Em M. Cachioni (Org.), Quem educa os idosos? Um estudo sobre professores de Universidades da Terceira Idade (pp. 177-200). Campinas, SP: Átomo e Alínea.

Diener, E. (1984). Subjective well-being. Psychological Bulletin, 95, 542-545.

Erikson, E. H. (1950). Childhood and society. New York, NY: Norton.

Erikson, E. H. (1986).Vital involvement in old age. New York, NY: Norton.

Erikson, E. H.(1998). O ciclo de vida completo (M. A. V. Veronese, Trad.). Porto Alegre: ArtMed. (Original publicado em 1997)

Freire, S. A. (2000). Envelhecimento bem-sucedido e bem-estar psicológico. Em A. L. Neri \& S. A. Freire (Orgs.), Eporfalar em boa velhice (pp. 21-31). Campinas, SP: Papirus.

Gardner. H. (1994). Estruturas da mente: A teoria das inteligências múltiplas. Porto Alegre: ArtMed.

Goleman, D.(1995). Inteligência emocional. Rio de Janeiro: Objetiva.

Goleman, D.(1999). Trabalhando com inteligência emocional. Rio de Janeiro: Objetiva.

Hedlund, J. \& Sternberg, R. J. (2002). Inteligências em excesso? Integrando as inteligências social, emocional e prática (R. C. Costa, Trad.). Em R. Bar-On \& J. D. A. Parker (Orgs.), Manual de inteligência emocional: Teoria, desenvolvimento, avaliação e aplicação em casa, na escola e no local de trabalho (pp. 111-131). Porto Alegre: Artmed. (Original publicado em 2000)

Keyes, C. L. M., Shmotkin, D. \& Ryff, C. D. (2002). Optimizing well-being: The empirical encounter of two traditions. Journal of Personality and Social Psychology, 82,1007-1022.

McAdams, D. P. \& St. Aubin, E. de (1992). A theory of generativity and its assessment throught self-report, behavioral acts, and narrative themes in autobiography. Journal of Personality and Social Psychology, 62, 1003-1015.

McAdams, D. P., Hart, H. M. \& Maruna, S. (1998). The anatomy generativity. Em D. P. MacAdams, H. M. Hart \& S. Maruna (Orgs.), Generativity and adult development: How and why we care for the next generation (pp. 7-43). Washington, DC: Americam Psychological Association.

McCrae, R. R. (2002). A inteligência emocional segundo a perspectiva do modelo da personalidade dos cinco fatores (R. C. Costa, Trad.). Em R. Bar-On \& J. D. A. Parker (Orgs.), Manual de inteligência emocional:Teoria, desenvolvimento, avaliação e aplicação em casa, na escola e no local de trabalho (pp. 198-206). Porto Alegre: Artmed. (Original publicado em 2000)

Mayer, J. D., Caruso, D. R. \& Salovey, P. (2002). Selecionando uma medida para inteligência emocional: Em defesa das escalas de aptidão (R. C. Costa, Trad.). Em R. Bar-On \& J. D. A. Parker (Orgs.), Manual de inteligência emocional: Teoria, desenvolvimento, avaliação e aplicação em casa, na escola e no local de trabalho (pp. 237 251). Porto Alegre: Artmed. (Original publicado em 2000)

Mayer, J. D. \& Salovey, P. (1997). What is emotional intelligence? Em P. Salovey \& D. J. Sluyter (Org.), Emotional development and emotional intelligence; educational implications. (pp. 3-31). New York: Basic Books.

Neri, A. L. (1999). Fundamentos para uma escala de geratividade. Campinas, SP: UNICAMP/FAPESP. (Relatório de pesquisa não-publicado)

Neri, A. L. (2000). Qualidade de vida no adulto maduro: Interpretações teóricas e evidências de pesquisa. Em A. L. Neri (Org.), Qualidade de vida e idade madura (pp. 9-55).Campinas, SP: Papirus.

Neri, A. L. (2002). Bienestar subjetivo en la vida adulta y en la vejez: Hacia una psicologia positiva en la América latina. Revista Latinoamericana de Psicologia, 34 , 55-74.

Queroz, N. C. (2003). Bem-estar psicológico e inteligência emocional entre homens e mulheres na meia-idade e velhice. Dissertação de Mestrado em Gerontologia não-publicada, Faculdade de Educação, Universidade Estadual de Campinas. Campinas, SP.

Phillips, L. H., Maclean, D. J. \& Allen, R. (2002). Age and the understanding of emotions: Neuropsychological and sociocognitive perpectivies. Journal of Gerontology. Series B - Psychological Sciences and Social Sciences, 57, 526-530.

Ryff, C. D. (1989a). Beyond Ponce de Leon and life satisfaction: New directions in quest of successful aging. International Journal of Behavioral Development, 12, 3555.

Ryff, C. D. (1989b). Happiness is everything, or is it ? Explorations on the meaning of psychological well-being. Journal of Personality and Social Psychology, 57, 10691081.

Ryff, C. D. \& Essex, M. (1991). Psychological well-being in adulthood and old age: Descriptve markers and explanatory processes. Annual Review of Gerontology in Geriatrics, 11,144-171.

Ryff, C. D. (1995). Psychological well being in adult life. Current Directions in Psychological Science, 4, 99-104.

Ryff, C. D. \& Keyes, C. L. M. (1995). The structure of psychological well-being revisited. Journal of Personality and Social Psychology, 69, 719-727.

Salovey, P., Mayer, J. D. (1990). Emotional intelligence. Imagination, Cognition and Personality, 9, 185-211.

Seligman, M. E. P. \& Csikszentmihalyi, M. (2000). Positive pychology: An introduction. American psychology, 55, 5-14.

Siqueira, M. M. M., Barbosa, N. C. \& Alves, M. T. (1999). Construção e validação fatorial de uma medida de inteligência emocional. Psicologia: Teoria e Pesquisa, 15, 143-152.

Sternberg, R. J. \& Grigorenko, E. L. (2002). A inteligência prática e o seu desenvolvimento (R. C. Costa, Trad.). Em R. Bar-On \& J. D. A. Parker (Orgs.), Manual de inteligência emocional: Teoria, desenvolvimento, avaliação e aplicação em casa, na escola e no local de trabalho (pp. 165-184). Porto Alegre: Artmed. (Original publicado em 2000)

Recebido: 09/12/2003

$1^{a}$ Revisão: $16 / 04 / 2004$

Última revisão: 05/11/2004

Aceite Final: 22/11/2004

Sobre as autoras

Nelma CairesQueroz é Psicóloga, Especialista e Mestre em Gerontologia. É Doutoranda em Educação pela Universidade Estadual de Campinas. Anita Liberalesso Neri é Psicóloga e Pedagoga. É Professora Titular na Faculdade de Educação da Universidade Estadual de Campinas. 